\title{
Novel Anti-Inflammatory and Wound Healing Controlled Released LDH-Curcumin Nanocomposite Via Intramuscular Implantation, In-Vivo Study
}

\author{
Mahmoud $\mathbf{R}^{1}$, Safwat $\mathbf{N}^{2}$, Fathy $\mathbf{M}^{3}$, Mohamed $\mathbf{N}^{4}$, \\ El-Dek $\mathrm{S}^{5}$, El-Banna $\mathrm{H}^{6}$, Farghali $\mathrm{A}^{5}$ and El-Ela \\ FIA ${ }^{\text {7* }}$ \\ ${ }^{1}$ Department of Chemistry, Faculty of Science, Beni-Suef \\ University, Egypt \\ ${ }^{2}$ Department of pathology, Faculty of Veterinary \\ Medicine, Beni-Suef University, Egypt \\ ${ }^{3}$ Department of Surgery, Anesthesiology and Radiology, \\ Faculty of Veterinary Medicine, Beni-Suef University, \\ Beni-Suef, Egypt \\ ${ }^{4}$ Department of Chemistry, Faculty of Science, Beni-Suef \\ University, Beni-Suef, Egypt \\ ${ }^{5}$ Department of Materials Science and Nanotechnology, \\ Faculty of Postgraduate Studies for Advanced Sciences, \\ Beni-Suef University, Egypt \\ ${ }^{6}$ Department of Pharmacology, Faculty of Veterinary \\ Medicine, Cairo University, Cairo, Egypt \\ ${ }^{7}$ Department of Pharmacology, Faculty of Veterinary \\ Medicine, Beni-Suef University, Egypt \\ *Corresponding author: Fatma I Abo El-Ela, \\ Department of Pharmacology, Faculty of Veterinary \\ Medicine, Beni-Suef University, 62511, Egypt
}

Received: May 12, 2021; Accepted: J uly 01, 2021; Published: July 08, 2021

\begin{abstract}
One of the most common problems in wounds is delayed healing and complications such as infection. Therefore, the need for novel materials accelerates the healing of wounds especially abdominal wounds after surgery besides high efficiency and safety is mandatory. The rate of wound healing, anti-inflammatory and biocompatibility of Zn-Al LDH alone and loaded with Curcumin was screened via in-vivo assays through intramuscular implantation in rat abdominal wall with intact peritoneum cavity. The implanted drugs were formed through Curcumin loaded into LDH of Zn-Al with drug release of 56.78 $\pm 1.51 \%$ within $24 \mathrm{~h}$. The synthesized nanocomposite was characterized by thermal analysis, X-ray diffraction, Field emission scanning microscopy, high resolution transmission electron microscope and BET surface area. The integrity of blood circulation, inflammatory signs, wound healing rate, capacity of tissue integration, antigenicity and composite biocompatibility, auto fluorescence ability of collagen bundles and the tensile strength of the muscle were assessed histopathologically after 7 and 30 days post-implantation. Excellent wound healing ability was achieved with shortest length between the wound gap edges and higher tensile strength of the muscle. Besides emit florescence very well followed by good healing and tensile muscles strength in Curcumin while very low strength with scar formation in Curcumin-Zn/Al-LDH in both acute and chronic wound. No signs of inflammation in Curcumin \& Zn-Al LDH. No vessels obstruction or bleeding observed in both Zn/Al-LDH and Curcumin more than nanocurcumin and control which examined through candling. Good healing \& infiltrated immune cells in same groups through histopathological examination. This work supports the anti-inflammatory, wound healing and biocompatibility of both LDH and Curcumin with living matter, increasing their biomedical applications in this era with safety and increasing efficacy with prolonged drug release.
\end{abstract}

Keywords: Curcumin; Zn-Al LDH; Nanocomposite; Auto fluorescence; Wound; Rats

\section{Introduction}

Layer Double Hydroxides (LDH's) are anionic clay materials with structure similar to brucite [1] and chemical formula [M(II) $\left.(1-\mathrm{x}) \mathrm{M}(\mathrm{III}) \mathrm{x}(\mathrm{OH})_{2}\right]^{\mathrm{x}+}\left(\mathrm{A}^{\mathrm{n}-}\right)_{\mathrm{x} / \mathrm{n}} \cdot \mathrm{yH} \mathrm{H}_{2} \mathrm{O} \cdot \mathrm{M}(\mathrm{II})$ is a divalent cation such as $\mathrm{Mg}, \mathrm{Ni}, \mathrm{Zn}, \mathrm{Cu}$ or $\mathrm{Co}$ and $\mathrm{M}(\mathrm{III})$ is a trivalent cation such as $\mathrm{Al}, \mathrm{Cr}$, Fe or $\mathrm{Ga}$, while $\mathrm{A}^{\mathrm{n}-}$ is an anion of charge such as $\mathrm{CO}^{-}, \mathrm{Cl}^{-}, \mathrm{NO}^{-}$ or organic anions, Figure 1 [2] illustrated the structure of $\mathrm{LDH}$, which consists of outer layer positively charge metal hydroxide and interlayer of negative anions to counter balance the overall charge. LDHs are imposing much more attention as a biocompatible material due to their fascinating properties ion exchange capacities, ability to intercalate anions, high water retention capacity, low toxicity and large surface area and pore size $[3,4]$. The mentioned characteristic features make LDH qualified to be used in medical sector such as antimicrobial [5], anti-inflammatory, antifungal [6], wound healing [7], drug delivery, drug release [8], and anticancer [9]. Additionally LDHs are used in different applications and sectors. According to Scopus statistics in last few decades, there are growing in the number of published articles on LDH and their application, which indicate the expansion of interest in $\mathrm{LDH}$ shown in Figure 2. (to be transferred to the $1^{\text {st }}$ paragraph in the introduction).

The peritoneum and area of the abdominal cavity are considered the most active areas for the surgical activity, healing of the peritoneal surfaces with subsequent adhesion formation remain one of the most clinical problems at surgery and post-operative, different studies had been made for understanding the pathophysiology of these responses remains elusive [10].

Maintenance of drug levels for a specified period of time with maintained drug concentration, lower dosing, higher efficacy and bioavailability are the main advantages for the controlled or sustained drug release. Controlled drug delivery is a way for delivering the drug at a predetermined rate, for locally or systemically and for a specified period of time. In surgery the implanted materials should be biocompatible, inert and safe or non-toxic [11].

Healing process of any wound is an interaction of a complex
Austin J Pharmacol Ther - Volume 9 Issue 4 - 2021 ISSN: 2373-6208 | www.austinpublishing group.com El-Ela et al. (c) All rights are reserved
Citation: Mahmoud R, Safwat N, Fathy M, Mohamed N, El-Dek S, El-Banna H, et al. Novel Anti-Inflammatory and Wound Healing Controlled Released LDH-Curcumin Nanocomposite Via Intramuscular Implantation, In-Vivo Study. Austin J Pharmacol Ther. 2021; 9(4).1145. 


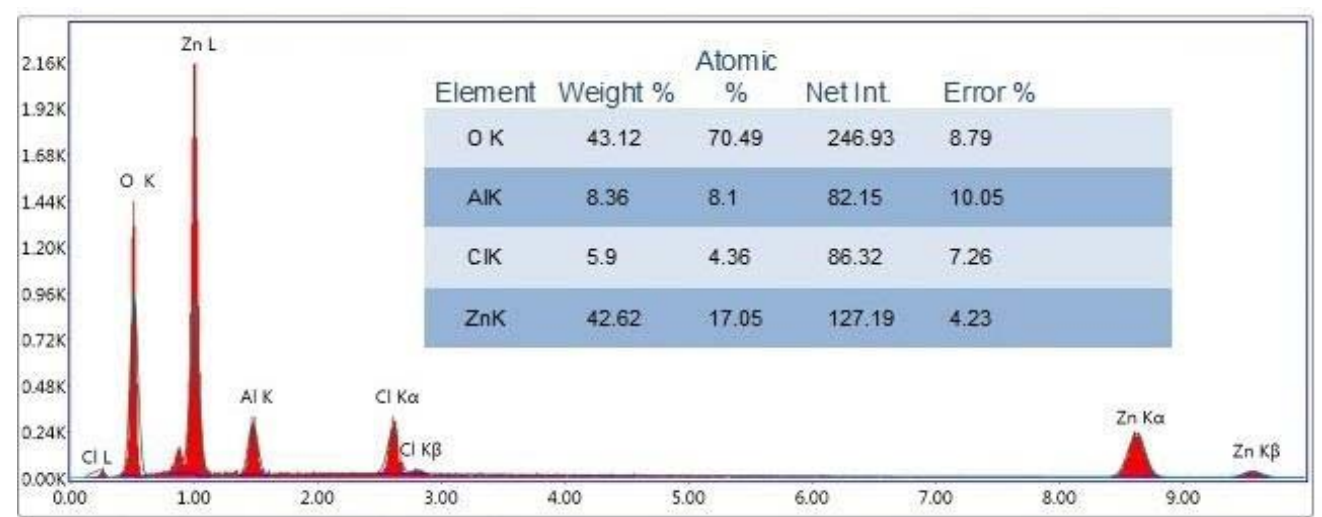

Figure 1: EDAX of Zn-Al LDH.

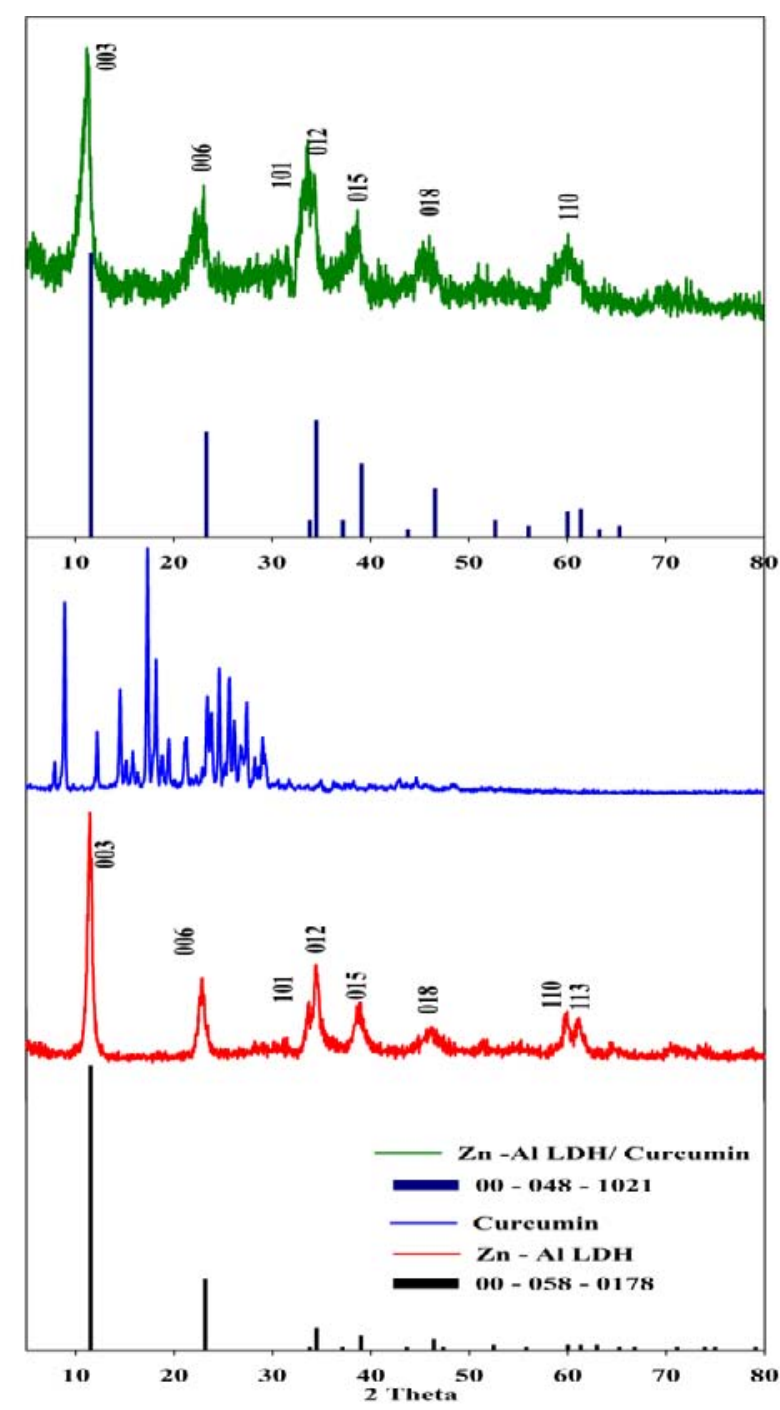

Figure 2: XRD patterns of ICCD card (00-058-0178), Zn-AI LDH, Curcumin, ICCD card (00- 048- 1021), and (Zn-AI LDH/Curcumin) nanocomposite.

cascade of cellular events in the injured area that generates resurfacing, reconstitution, and restoration of the tensile strength [12]. Induction of wound in muscle include proliferative phase where

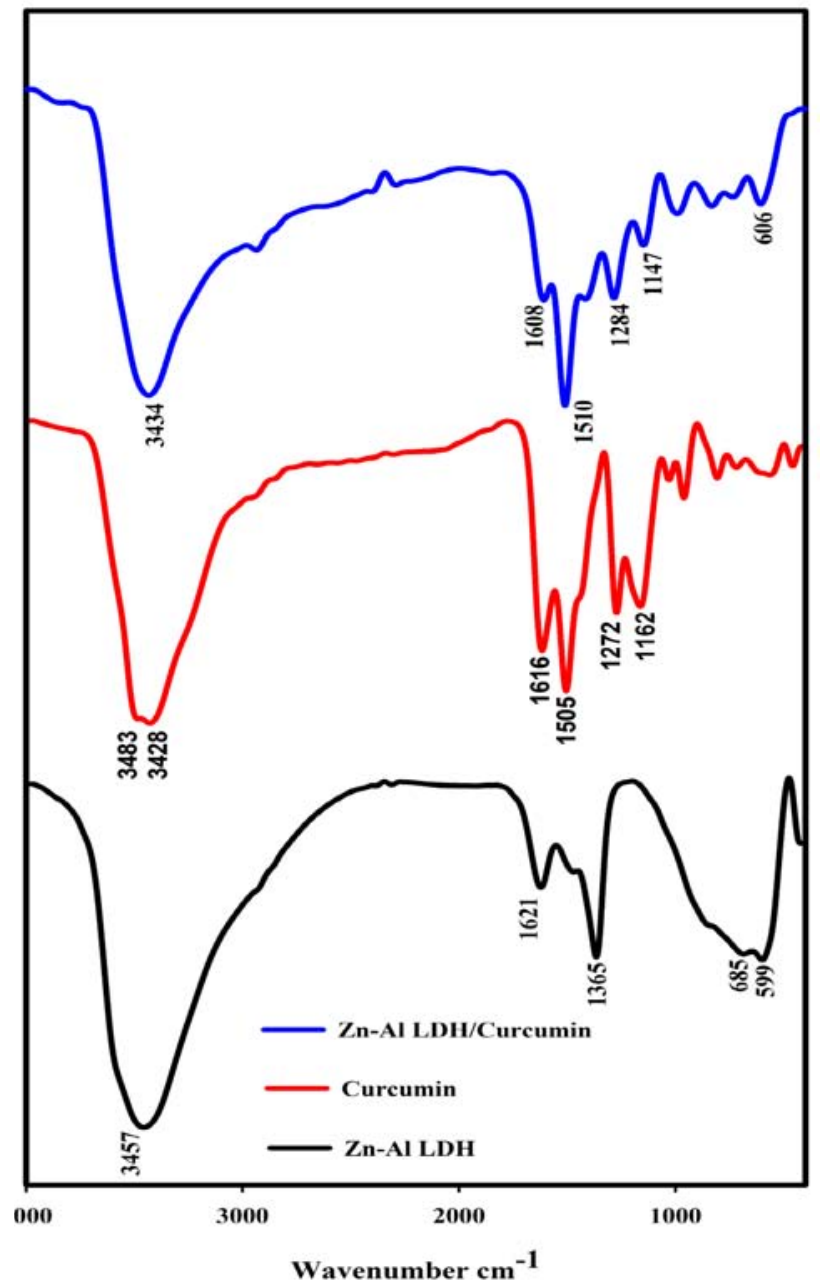

Figure 3: FTIR of Zn-AI LDH, Curcumin, and Zn-AI LDH/Curcumin.

fibroplasia; specialized fibroblasts termed myofibroblasts, which resemble contractile smooth muscle cells [12] and angiogenesis occur. Meanwhile, granulation tissue forms and the wound begin to contract. Finally, during the maturation phase, collagen forms tight cross-links to other collagen and with protein molecules, increasing the tensile strength of the scar present between muscle edges [12]. 
Importance of flurence (check spelling and meaning), [13] reported that many tissue components have an intrinsic fluorescence including health muscle fibers as well as collagen and elastic connective tissue.

Curcumin (Diferuloylmethane) is a hydrophobic polyphenolic compound with chemical structure [1,7-bis(4-hydroxy-3methoxyphenyl)-1,6-heptadiene-3,5-dione] [14] Shown in Figure 3. Curcumin is the active component and a major yellow phytochemical compound in turmeric (Curcuma longa), which has been used in the traditional medicine in south East Asia countries, because their power of treatment against most chronic disease [15]. Curcumin possess many biological and pharmacological properties, which make it a good candidate in a diversity of biomedical applications such as anticancer, antioxidant, antiviral, anti-inflammatory and drug delivery applications [16-18]. (It is preferred to write a small paragraph on your previous work on LDH in wound healing and results.

Completing our series of work on LDH nanocomposite, we decided to throw light on how LDH-Curcumin could help in accelerating healing procedure as compared with pure curcumin.

The main aim of this study is to help the rapid healing of intraabdominal surgery in a controlled release manner through natural controlled nanocomposite in shorter time. Herein, the nanocomposite was prepared and characterized via several techniques for better descrition of its physico-chemical features. The evaluation depends upon both macroscopic and microscopic alterations in rectus abdominis muscle of male albino rats after surgical inducted wound (Table 1). Moreover, a comparative investigation between the healing process between three different treatments (pure curcumin common preparation and $\mathrm{Zn}-\mathrm{Al} \mathrm{LDH}$ Curcumin nanocomposite).

\section{Materials and Methods}

\section{Materials and reagents}

All LDH precursors were prepared using chloride salts, and were purchased from Alpha Chemika, India, and Oxford Laboratory Reagent, India. Sodium hydroxide $(\mathrm{NaOH})$ was purchased from Piochem for laboratory chemicals, EGYPT, and hydrochloric acid $(\mathrm{HCl})$ was obtained from Carlo Erba reagents. All chemicals had a high degree of purity. Curcumin pure natural powder with $100 \%$ purity obtained from Pharma Swede Pharmaceutical Company, Egypt.

\section{Synthesis of Zn-AI-LDH and Loading of Curcumin on Zn- Al-LDH}

Zinc chloride and Aluminum chloride (i.e. $\mathrm{Zn}$ : Al molar ratio of 4:1) were dissolved in $100 \mathrm{~mL}$ distilled water. $2 \mathrm{M}$ Sodium hydroxide $\mathrm{NaOH}$ was added drop wise until complete precipitation at $\mathrm{pH}$ 8.0.The precipitate suspension was stirred for 20 hours at room temperature, filtered, washed several times with bidistilled water and finally dried at $40^{\circ} \mathrm{C}$.

Zn-Al LDH/Curcumin Nanocomposite (i.e. Zn: Al: Curcumin molar ratio of 4:1:0.5) was synthesized by repeating the above mentioned procedures and adding a solution of Curcumin (1.5 $\mathrm{gm}$ of curcumin dissolved in $50 \mathrm{ml}$ ethanol) to the medium before precipitation at $\mathrm{pH} 8.0$ using droplets of $\mathrm{NaOH}$. The Curcumin-LDH-

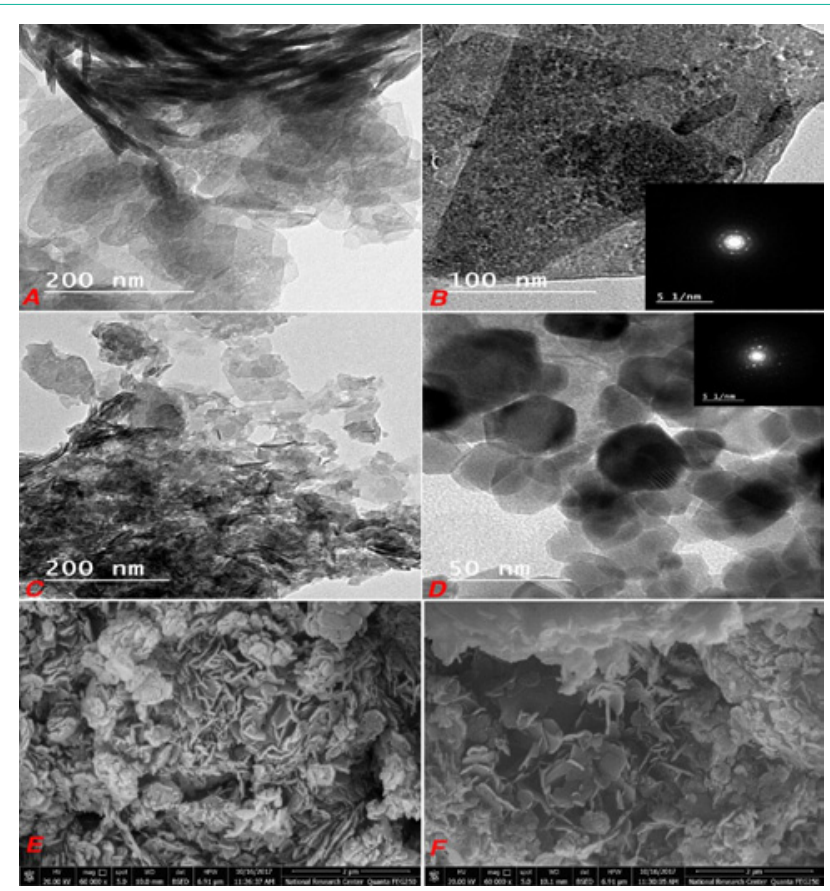

Figure 4: Low and high magnification HRTEM images of Zn-Al LDH (a and b), Zn-Al LDH/curcumin (c and d) and the FESEM images of Zn-AI LDH (e and $\mathrm{f}$ ).

precipitate suspension was stirred at room temperature for 20 hours, filtered, washed thoroughly for several times, and dried at $40^{\circ} \mathrm{C}$.

\section{Characterization}

The phase formation and crystallinity of the nanocomposites were characterized by XRD technique. The vibrations of material chemical bond were examined by Fourier Transform Infra-red (FT-IR, Bruker Vertex 70). High resolution Transmission electron microscope (HRTEM, JEOL-JEM 2100) were used to characterize the microstructure of all nanocomposites. The morphology and elemental analysis (EDAX) of $\mathrm{Zn}-\mathrm{Al} / \mathrm{LDH}$ were characterized by Field Emission Scanning Electron Microscope (FESEM, Quanta FEG $250)$ to confirmer ratio of $\mathrm{Zn}-\mathrm{Al} \mathrm{LDH}(\mathrm{Zn}: \mathrm{Al}=4: 1)$ which are shown in Figure 4. The hydrodynamic size and zeta potential were studied (experimentally optimized) by a Malvern (Malvern Instruments Ltd), using the methodology mentioned in our reported work [19]. The BET specific surface area, specific pore volume, and pore sizes of the adsorbent materials were determined by $\mathrm{N} 2$ adsorption isotherms using an automatic surface analyzer (TriStar II 3020, Micromeritics, USA) and the samples preparation was mentioned in our previous work [5]. Thermogravimetric analysis TGA /DTA was performed under N2 gas with a SDT Q600 V20.9 Build 20 at a heating rate of $10^{\circ} \mathrm{C} / \mathrm{min}$.

Table 1: Displaying the all data analysis about between two healing edges of rectus abdominis muscle.

\begin{tabular}{|c|c|c|c|c|c|c|}
\hline & Area & Min & Max & Perim. & Angle & Length \\
\hline G.I & 754 & 58.852 & 254.989 & 753.335 & 179.924 & 753.335 \\
\hline G.II & 516 & 10.667 & 245.974 & 514.674 & -89.777 & 514.674 \\
\hline G. III & 864 & 11.869 & 254.003 & 862.503 & -29.119 & 862.503 \\
\hline G.IV & 452 & 4.841 & 253.135 & 451.100 & -65.535 & 451.100 \\
\hline
\end{tabular}



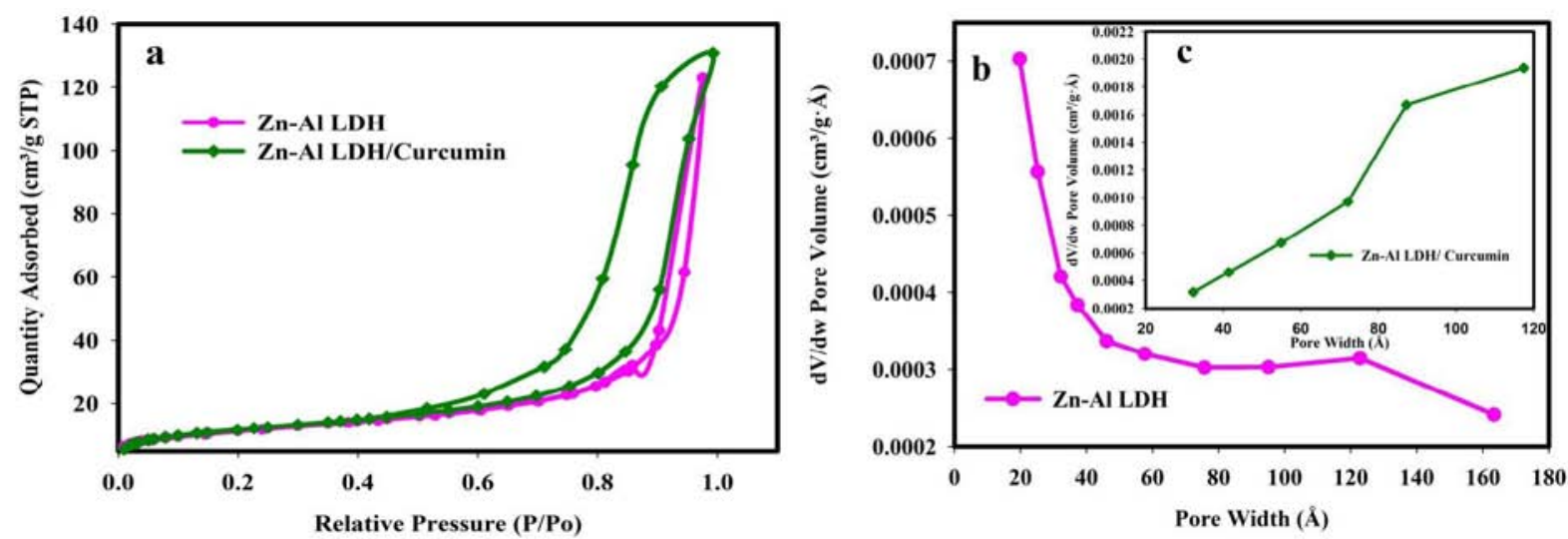

Figure 5: N2 adsorption-desorption isotherm (a) and pore size distribution (b and c) of Zn-Al LDH and Zn-Al LDH/curcumin

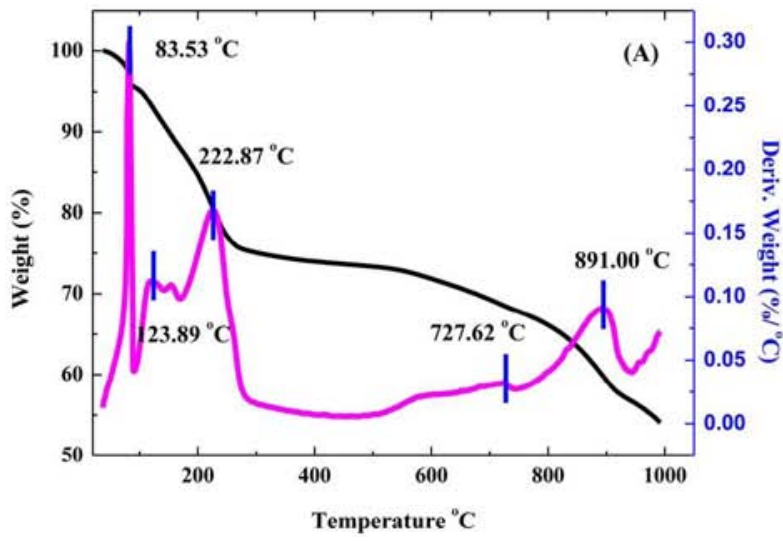

Figure 6: TGA/DTA curves of Zn-AI LDH (A) and Zn-Al LDH/curcumin (B).

\section{Drug release}

Release study was performed using dissolution apparatus I (VanKel, Agilent technologies, USA). A representative amount of $10 \mathrm{mg}$ Curcumin immersed in $500 \mathrm{ml}$ phosphate buffer $\mathrm{pH} 7.4$ containing $0.1 \%$ Tween 80 . Two $\mathrm{ml}$ samples were withdrawn in predetermined time intervals and drug concentration was measured at $424 \mathrm{~nm}$ using UV spectrophotometer. To ensure that sustained release profile is not due to membrane, curcumin dispersion in the same concentration with Curcumin SLNs was studied under the same condition for release. The drug release was calculated as following equation:

Drug release $\%=$ Amount of TXC released at time $/$ Initial amount of TXC encapsulated in the noisome $\mathrm{x} 100$.

\section{Animals}

This work was conducted on twenty-four adult male albino rats (divided into four groups of six rats) weighing range from 150 to 200 gm., and were reared on standard diet daily with continuous available water for 24 hour. The experimental study was carried out after 7 days acclimatization for the rats with standard protocol of 12 hour light and dark and of each group in its specific metal cage. The experiment was subjected to the Institutional Animal Ethics Committee (IAEC) at Beni-Suef University. The Institutional Committee for Animal

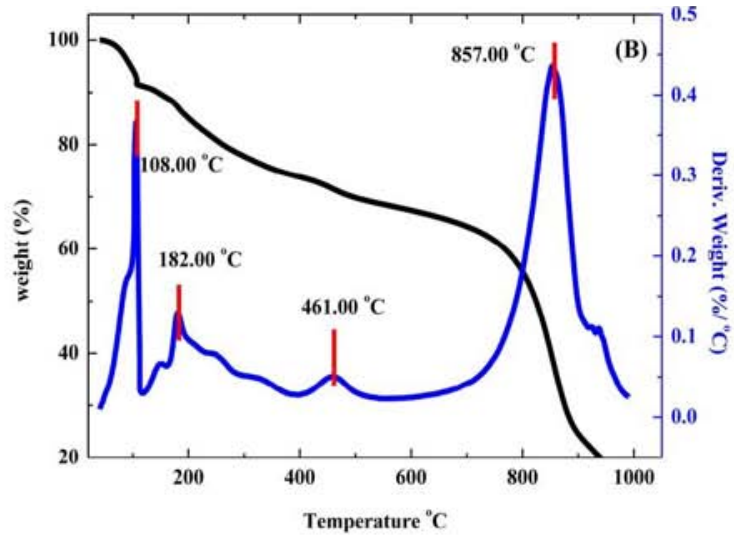

Care at Beni-Suef University, Egypt, approved all the performed procedures. Whereas, Animal handling, study weight, dosing and the performed procedures were approved according to the care guidelines. These animals were housed under standard environmental conditions. Rats were obtained from lab animal unit; Department of Physiology, Faculty of Veterinary Medicine, Beni-Suef University, Egypt. Rats were kept in standard laboratory conditions $22 \pm 3^{\circ} \mathrm{C}$, $60 \pm 5 \%$ humidity and a 12 hours light/dark cycle. Animal handling including weighing and gavage procedures were carried out in accordance with and approved by the institutional animal care and use committee, Faculty of Veterinary Medicine, Beni-Suef University (Protocol of animal rights for laboratory experiments).

\section{Intramuscular Implantation assessment}

The animals were anaesthetized by intra-peritoneal injection mixture of $10 \mathrm{mg} / \mathrm{kg}$ xylazine $\mathrm{HCl}$ (Xyla-Ject 2\% ADWIA Co., A.R.E.) and $100 \mathrm{mg} / \mathrm{kg}$ ketamine $\mathrm{HCl}$ (Ketamar 5\% sol. Amoun Co. A.R.E) [20]. The animals were prepared for aseptic surgery; surgical skin incision of $2 \mathrm{~cm}$ was done in the midline and creates the blunt dissection between the external and internal abdominal oblique muscles. The peritoneal cavity remained intact without perforation (Plate 1(Figure 1)) [21].

The drugs were poured into the surgical abdominal gap made in rectus abdominis muscles using insulin syringe after removing 
of its tip (Plate 1(Figure 2)). In Group I (control), the induction of surgical aseptic wound without treatment, In Group III, the wound was treated with Nanocomposite ZnAl LDH/Curcumin (Plate 1(Figure 3\&6)), Group II, topically treated by Curcumin only (Figure $4 \& 7)$. Finally, in Group IV, the wound was topically treated by $\mathrm{Zn} /$ Al LDH only (Figure 5\&8). All muscle dissections were sutured by $4 / 0$ vicryl (coated vicryl, polygalactin 910, ETHICON limited, UK) (Plate 1(Figure $9 \& 10)$ ) and the drug area inside the two abdominal muscles was about $(2 \times 3 \mathrm{~cm})$. The skin closure of all animals was done with $4 / 0$ continuous nylon suture. All surgical procedures were implemented under aseptic conditions. The tissues holding the tablets were collected after 7 and 30 days after implantation under the same general anesthesia.

\section{Candling}

Using of a strong light lamp for assessing the vasculature in the injured area in all animals.

\section{Gross examination before euthanasia of animals}

The injured area was examined grossly in all animals in all groups, and photographed for recording any alterations present in the area.

\section{Histopathological study}

Tissue samples were collected on time of one week and one month postoperative for histopathological studies. Tissue specimens were fixed in $10 \%$ neutral buffered formalin for about two days. The specimens were processed by paraffin embedding method, sectioned 5-7 $\mu$ and stained with Hematoxylin and Eosin according to [22].

\section{Auto fluorescent study}

Also in the time of one month postoperative, stained sections routinely with hematoxylin and eosin (Haematoxylin: Fluka, AG, Switzerland, Buchs SG-Eosin Y: alcohol and water soluble, Winlap, $\mathrm{UK}$ ), were mounted in fluorescence- free D-P-X mountant (LOBA Chemie, India), The H\&E stained tissue sections were examined under fluorescence microscope to estimate the intrinsic autofluorescence emitted from collagen in between the two wound gap edges [13]. (Euromex Oxion microscope Netherlands, 3 Watt LED for transmitted light, 85-240 V operation Reflected 100 W mercuryvapor light sources for fluorescence, with power supply for 85-240 V operation); the computer optimized design of the Oxion ensures high stability and durability which results in an advanced ergonomical all-round microscope. All Fields were microphotographed optically using software.

\section{Image analysis}

This technique was applied on microphotographs taken from the software of fluorescence microscope to determine and to compare the length of autofluorescent emission of gap junction healing among four groups by using image $\mathrm{j}$ software (http://rsb.info.nih.gov/ij/) using the same power field magnification.

\section{Results and Discussion}

XRD patterns of $\mathrm{Zn}-\mathrm{Al} \mathrm{LDH}$, curcumin and nanocomposite ( $\mathrm{Zn}$ $\mathrm{Al} \mathrm{LDH/curcumin)}$ are shown in Figure 5. The native $\mathrm{Zn}-\mathrm{Al} \mathrm{LDH}$ diffraction peaks are agreement with that of the synthetic hydrotalcitelike compound in ICDD card no. (00- 058-0178), were indexed to the rhombohedral crystal structure with space group of $\mathrm{R}-3 \mathrm{~m}$.

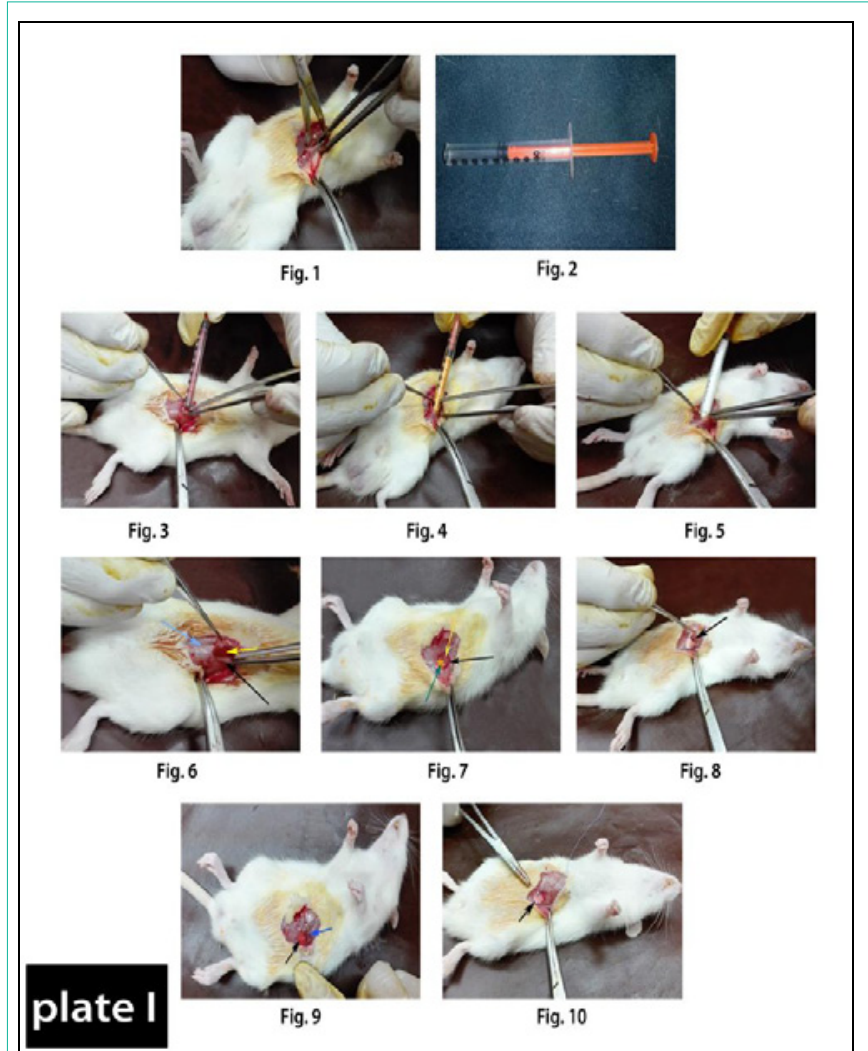

Plate 1: Showing method of surgical incision of the rectus abdominis muscle pouring in between the incision of different powders of drugs by using new convential method.

Figure 1: Showing the surgical dissection between internal and externa abdominal obliques muscles.

Figure 2: Showing the insulin syringe after remove its tip for drugs application as a new convential method for drug powder pouring.

Figure 3: Showing the topical application of Nano-material of Curcumin $+\mathrm{Zn}-$ AI LDH in between the incised wound of rectus abdominis muscle.

Figure 4: Showing the topical application of Curcumin alone in between the incised wound of rectus abdominis muscle.

Figure 5: Showing the topical application of Nano-material Zn-AI LDH alone in between the incised wound of rectus abdominis muscle.

Figure 6: Showing the powder of Nano-material of Curcumin+Zn-Al LDH (yellow arrow) present between the external abdominal obliques muscles (blue arrow) and the internal abdominal obliques muscles (black arrow).

Figure 7: Showing the powder of Curcumin (blue arrow) present between the external abdominal obliques muscles (black arrow) and the internal abdominal obliques muscles (yellow arrow).

Figure 8: Showing the powder of Nano-material Zn-Al LDH (black arrow) present between the external abdominal obliques muscles and the internal abdominal obliques muscles.

Figure $9 \&$ 10: Suturing of muscle dissections by $4 / 0$ vicryl (arrows).

According to Debye Scherrer,s formula, the value of the crystallite size is calculated to be $23.1 \mathrm{~nm}$. The basal reflections corresponding to 003 and 006 planes confirmed the layered structure of LDH. In native $\mathrm{Zn}-\mathrm{Al} \mathrm{LDH}$ the interlayer space (basal spacing) of $\mathrm{d}(003)=0.77$ $\mathrm{nm}$ and $\mathrm{d}(006)=0.38 \mathrm{~nm}$ agree with that reported in the literature (Kuehn and Poellmann 2010). XRD data of curcumin revealed strong reflections in the $\left(2^{\ominus}\right)$ range of $10-30^{\circ}$ which pointed to the crystalline nature of the used curcumin $[15,17]$. The nanocomposite $\mathrm{Zn}-\mathrm{Al} \mathrm{LDH} /$ curcumin was successfully obtained as confirmed by the comparing with the ICDD card no.(00- 048- 1021) [23]. Their 


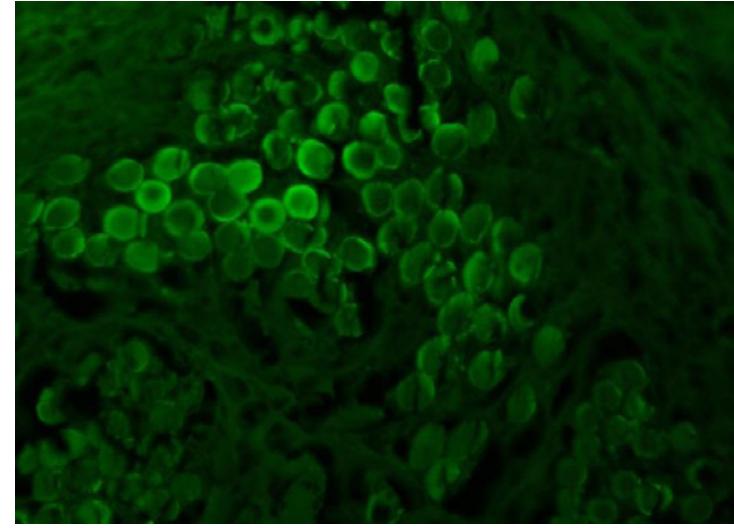

Figure 7: Normal healthy smooth muscle bundles emitting intrinsic autofluorescence when examined by fluorescent microscope. This picture is the control positive of the intrinsic autofluorescence of the normal healthy muscle bundles, and this ability disappear when occur degenerative changes to this muscle like of operation which made in all groups.

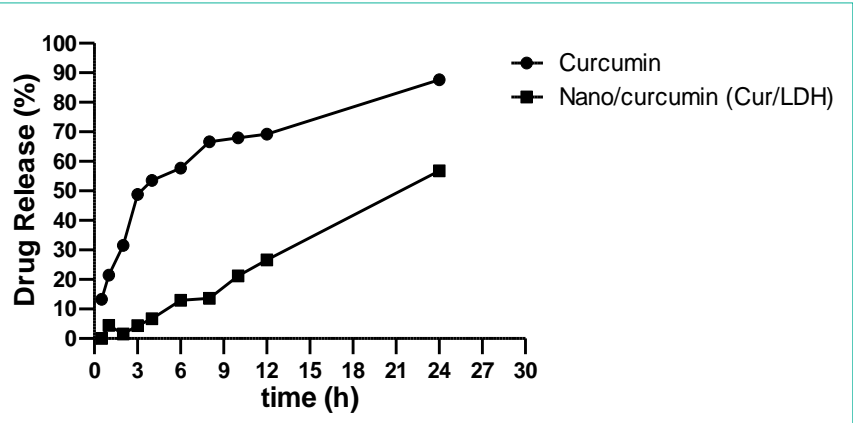

Figure 8: In vitro release profiles of Curcumin from Curcumin/LDH formula $(n=3 \pm S D)$.

reflections were indexed as the planes (003), (006), (101), (012), (015), (018) and (110) and the crystal symmetry was kept as rhombohedral the crystallite size is $29.2 \mathrm{~nm}$. The basal spacing at lower $\left(2^{\ominus}\right) 003$ and 006 is 0.78 and $0.38 \mathrm{~nm}$ with no significant change in the $\mathrm{d}$ spacing and lack of crystallinity than the native LDH due to the amorphous or disordered-crystalline phase of curcumin. The broadening and low intensities of XRD peaks of nanocomposite compared to those of native LDH stable structure pointed to lowered crystallite of the nanocomposite.

FTIR transmittance spectra of curcumin, Zn-Al LDH and Zn$\mathrm{Al} \mathrm{LDH/} \mathrm{curcumin} \mathrm{nanocomposite} \mathrm{were} \mathrm{shown} \mathrm{in} \mathrm{Figure} \mathrm{6.} \mathrm{The}$ significant bands of curcumin are at $3476 \mathrm{~cm}^{-1}$ corresponding to the phenolic $\mathrm{O}-\mathrm{H}$ stretching vibrations, the band at $1607 \mathrm{~cm}^{-1}$ related to the stretching vibration of the benzene ring skeleton, the peak at 1511 $\mathrm{cm}^{-1}$ represent the mixed $\mathrm{C}=\mathrm{O}, \mathrm{C}=\mathrm{C}$ vibrations, and the peak at 1261 $\mathrm{cm}^{-1}$ corresponding to the stretching vibration of Aromatic-O [11,24]. In native $\mathrm{LDH}$, peak at $3400 \mathrm{~cm}^{-1} \mathrm{can}$ be ascribed to the stretching mode of $\mathrm{OH}$ group with hydrogen bonding of interlayer water molecules. The peak located at $1357 \mathrm{~cm}^{-1}$ is assigned to the vibration of the $\mathrm{Cl}$ - groups in the LDH interlayer. The bands at approximately 685 and $599 \mathrm{~cm}^{-1}$ arises from metal-oxygen bonds $\mathrm{M}-\mathrm{O}$ vibration [25]. In nanocomposite, there are $\mathrm{O}-\mathrm{H}$ stretching, the $\mathrm{C}=\mathrm{O}$ stretching and methoxy C-O stretching vibrations of Curcumin within LDH

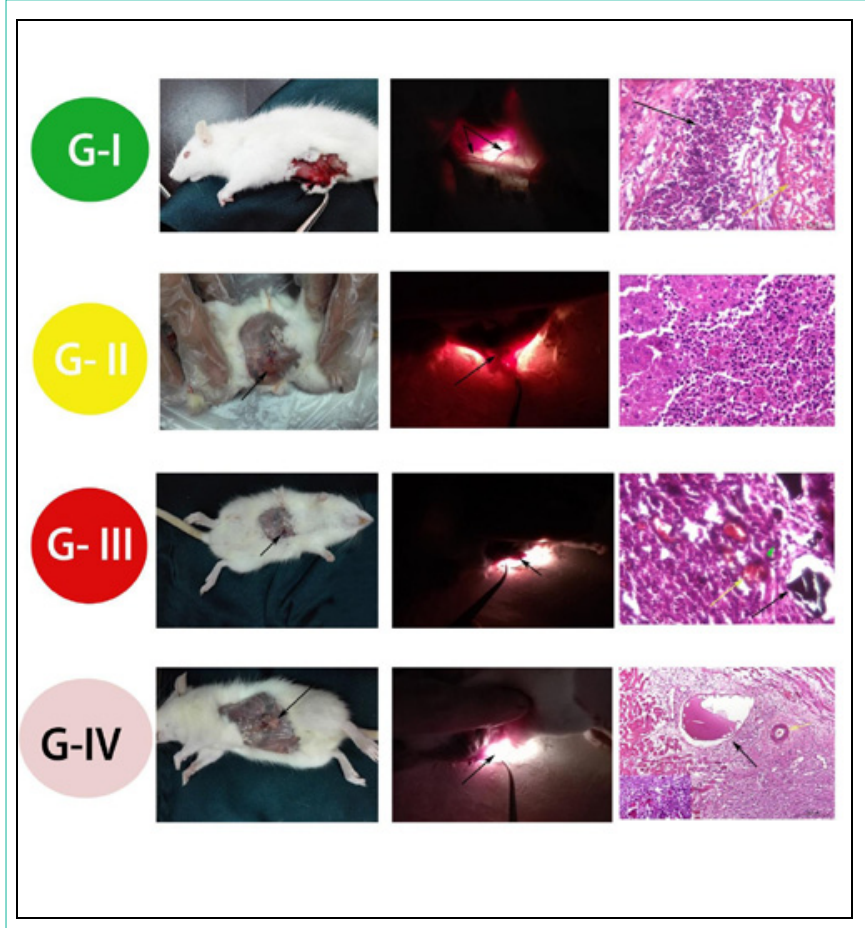

Plate 2: Showing the candling, gross examination, and histopathologica examination of the different four groups, one week (1w) postoperative.

G-I (Control group): Grossly: Instance of congestion associated with minimal hemorrhagic spots, beginning of proliferative phase (black arrow) at the site of induced wound.

Candle: Presence of prominent congested blood vessels at the site of wound (two black arrows).

Histopathologically: Photomicrograph of rat rectus abdominis muscle showing prominent congested blood capillaries (yellow arrow), as well as leucocytic cells infiltrates mainly by neutrophils and macrophages as the end of the inflammatory phase of wound healing (black arrow).

G-II (Group treated with Curcumin alone): Grossly: More or less normal wound site, only the drug ruminants observed at the site of wound (black arrow).

Candle: No congested blood vessels and drug residue present (black arrow).

Histopathologically: Photomicrograph of rat rectus abdominis muscle showing abundant leucocytic infiltrates at the site of induced wound.

G-III (Group treated with Curcumin loaded on Nano-material of Zn/AI -LDH): Grossly: No congestion at the site of wound except small residue of nano-powder.

Candle: No congested blood vessels but very small drug residue still present.

Histopathologically: Photomicrograph of rat rectus abdominis muscle showing remnant of drug residues (black arrow), minimal leucocytic infiltrations (green head arrow), as well as congested blood capillaries at site of wound (yellow arrow).

G-IV (Group treated with Zn/AI-LDH alone): Grossly: No congestion at the site of wound except abundant amount of non-absorbed residue of nanopowder (black arrow)

Candle: Presence of drug residue (black arrow)

Histopathologically: Photomicrograph of rectus abdominis muscle showing dilated blood capillary with edema (black arrow), with no congestion and mostly absence of leucocytic infiltrates.

shift to1510 $\mathrm{cm}^{-1}$ and $1608 \mathrm{~cm}^{-1}$ from $1506 \mathrm{~cm}^{-1}$ and $1616 \mathrm{~cm}^{-1}$ respectively. This indicates the formation of hydrogen bonds between $\mathrm{H}$ bond donor oxygen atoms and LDH layers. Accordingly, from FTIR analysis we conclude that the Curcumin molecules are strongly stabilized by the changing electron density within the interaction 


\section{conditions of $\mathrm{Zn}-\mathrm{Al} \mathrm{LDH}$.}

In Figure $7 \mathrm{a}$ and $7 \mathrm{~b}$ clarifies the layered structure of the prepared $\mathrm{Zn}-\mathrm{Al} \mathrm{LDH}$ as the sheet shape is predominant and the agglomeration is clear from the top view in Figure $7 \mathrm{a}$ and from the side view in Figure $7 \mathrm{~b}$ with more magnification. The Selected - Area Electron Diffraction (SAED) illustrated well defined diffraction rings pointing to the hexagonal symmetry of the $\mathrm{LDH}$ as previously mentioned in XRD section. By loading curcumin on LDH it's clear that the hexagonal platelet shape is predominant with less stacking in Figure $7 \mathrm{c}$ and $7 \mathrm{~d}$. The crystallinity get better as (contradiction) check with XRD the lattice spacing is seen at this magnification Figure $7 \mathrm{~d}$ the Curcumin role hear is obviously working as decrease the stacking and agglomeration between layers. A better explanation is due to its poor solubility in water therefore, we dissolve the Curcumin in ethanol and we expected that it act as exfoliator. In FESM micrographs are clarified in Figure 7e and $7 \mathrm{f}$ where flower like arrangement of hexagonal platelets is observed with less agglomeration.

In addition, the hydrodynamic diameters of $\mathrm{Zn}-\mathrm{Al} \mathrm{LDH}$ and $\mathrm{Zn}$-Al LDH /curcumin nanocomposite were measured to be 697.1, and $1363 \mathrm{~nm}$, respectively. The zeta potential was $35.70 \mathrm{mV}$ for LDH while that of nanocomposite was changed to $4.14 \mathrm{mV}$ after curcumin loading. The decreased electro positivity of the $\mathrm{Zn}-\mathrm{Al} \mathrm{LDH} /$ curcumin nanocomposites may be due to curcumin surface adsorption on LDH [29].

The surface area measurements and the pore size distribution of sorbents ( $\mathrm{Zn}-\mathrm{Al} \mathrm{LDH}$ and $\mathrm{Zn}-\mathrm{Al} \mathrm{LDH} /$ curcumin) were characterized by the $\mathrm{N} 2$ adsorption-desorption isotherms presented in Figure 8. All isotherms of the samples exhibited a pronounced increase in the adsorption at a relative pressure of $\mathrm{p} / \mathrm{po}>0.02$ which means Nitrogen uptake below p/po 0.02 was negligible and micropores were blocked. This indicates that all samples are classified as IV (mesoporous solids). According to IUPAC, pores sizes are classified into microporous, mesoporous and macroporous with pore diameter up to 2 , from 2 to 50 , and $>50 \mathrm{~nm}$, respectively [2].

The BET surface area of $\mathrm{Zn}-\mathrm{Al} \mathrm{LDH}$ and $\mathrm{Zn}-\mathrm{Al} \mathrm{LDH} /$ curcumin is $40.64 \mathrm{~m}^{2} / \mathrm{g}$ and $41.62 \mathrm{~m}^{2} / \mathrm{g}$ respectively. Low surface area of native $\mathrm{LDH}$ than its nanocomposite was attributed to the agglomeration of particles. The reason of low surface area of native LDH due to the preparation method in case of $\mathrm{Zn}-\mathrm{Al} \mathrm{LDH} /$ curcumin, ethanol is used to dissolve curcumin resulting in a decrease of agglomeration which results in a small different in surface area. HRTEM micrographs confirm these observation. The pore-size distribution. Peaks at $12 \mathrm{~nm}$ and $8.7 \mathrm{~nm}$ are depicted for $\mathrm{Zn}-\mathrm{Al} \mathrm{LDH}$ and $\mathrm{Zn}-\mathrm{Al} \mathrm{LDH} /$ curcumin, respectively. The lower value of pore size of $\mathrm{Zn}-\mathrm{Al} \mathrm{LDH} /$ curcumin is due to the blocked pores in $\mathrm{Zn}-\mathrm{Al} \mathrm{LDH}$ by curcumin confirming the successful loading of curcumin on LDH.

The $\mathrm{Zn}-\mathrm{Al} \mathrm{LDH}$ and $\mathrm{Zn}-\mathrm{Al} \mathrm{LDH} / \mathrm{Curcumin}$ nanocomposite were subjected to thermal analysis to determine the thermal stability and degradation temperatures. The TGA/DTA curves obtained for the samples are reported in. In TGA analysis of $\mathrm{Zn}-\mathrm{Al} \mathrm{LDH}$ and $\mathrm{Zn}-\mathrm{Al}$ LDH/Curcumin, one weight loss step was observed, and contributed to a total weight loss of $24.68 \%$ and $8.73 \%$ respectively. The weight loss due to the removal of chemisorbed and physisorbed water. The amount of hydration was significantly low compared to other inorganic $\mathrm{Zn}-\mathrm{Al} \mathrm{LDH}$ because the nano composite is less prone to being hydrated due to the intercalation of large organic anions. In the temperature range of $200-600{ }^{\circ} \mathrm{C}$, the nanocomposites showed a complete dehydroxylation of layers, together with partial combustion of the adsorbed Curcumin at the edges or surfaces of the crystallites $\mathrm{LDH}$, leading to an approximate weight loss of $25.56 \%$. In $\mathrm{Zn}-\mathrm{Al} \mathrm{LDH} /$ Curcumin a decomposition peak is observed at $360^{\circ} \mathrm{C}$ confirming the formation of composite molecules. A remarkable shift in DTA peaks confirms the increasing in the thermal stability of the curcumin/LDH Nano Composite. The LDH nanomaterial thus improves the stability of the anions because it provides protection for the adsorbed and intercalated anions against thermal combustion.

Healing of any wound differ according to the wound itself, the presence or absence of infection, age, health condition and /or dietary supply. All surgical procedures were performed in an identical way by a single surgeon. All animals were anesthesiazed and the surgery was made under a septic condition. All other factors were the same age, health condition and daily dietary supply.

The fact of adequate blood circulation that delivered to muscle fibers remains a starting point for efficient wound healing process. The importance here is highlighted owing to the micro vascular structure likely impacts muscle performance, hypothesized structural remodeling would occur in both the myofibers and microvasculature [12].

Our results of both candling and macroscopic appearance after one week of surgery revealed instance of prominent congested blood vessels at the site of induced wound in control group G-I (Plate 2 ). While the congestion not seen in the other groups unless drug remnants present only at the site of drugs implants G-II, G-III, and G-IV (Plate 2). Microscopical examination to the wound site to all groups revealed the presence of congested blood capillaries associated with leucocytic infiltrations but with different grades as in G-I (Plate 2). Prominent congested blood capillaries, as well as leucocytic cells infiltrates mainly by neutrophils and macrophages as the beginning of the inflammatory phase of wound healing, after that in G-II (Plate 2), the congestion was subsided but the abundant leucocytic infiltrates by neutrophils were prominent as curcumin reduce the time elapsed between different healing phases, acting on the inflammatory, proliferative and remodeling phases so, reducing the time needed for wound healing [12] so, the end of the inflammatory phase occur in this group. In G-III (Plate 2), the microscopical examination showed presence of some drug residues associated with minimal leucocytic infiltrations and prominent congested blood capillaries at site of wound that would suggest the speeding of wound healing through acceleration of healing stages, as normal wound healing consists of 4 phases: hemostasis, inflammation, proliferative, and remodeling. During the proliferative phase, tissue granulation associated with newly formed blood capillaries [27], and the minimal few number of leucocytes considered the end of the inflammatory phase. In G-IV (Plate 2), also occurs acceleration of healing phases, as there no congestion except edema present in the site of wound only.

In case of candling and macroscopic appearance after one month of surgery, mild congestion was observed in G.I (Plate 3), as the end of proliferative phase of wound healing. While in G-II (Plate 3), presence of mild congestion at wound site as the end of proliferative 


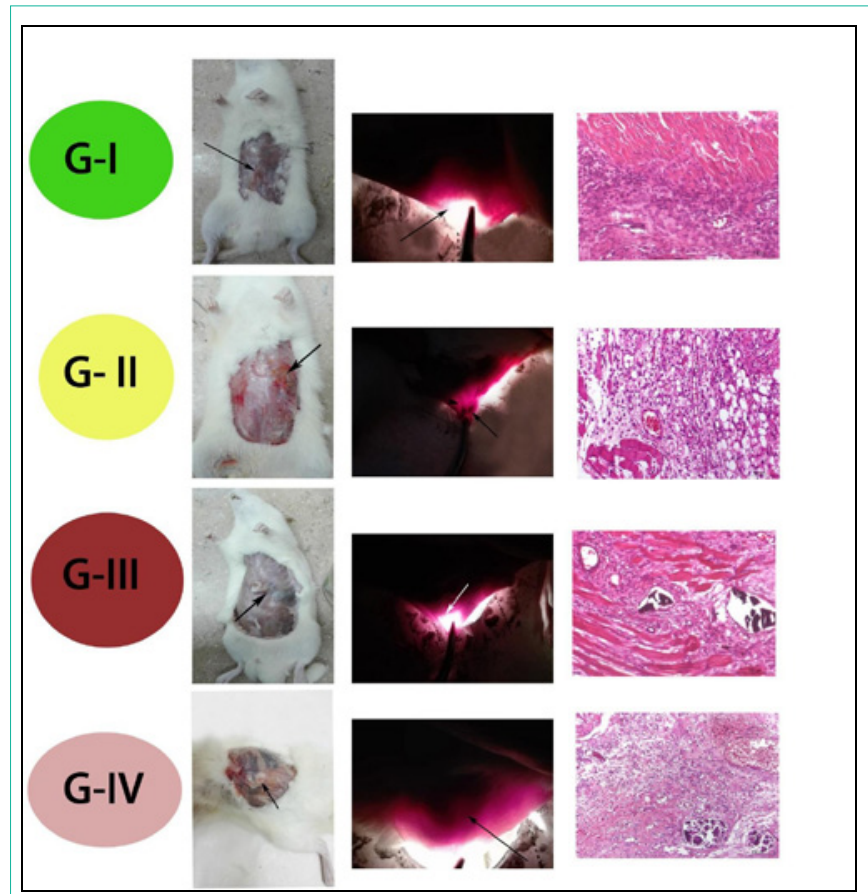

Plate 3: Showing the candling, gross examination, and histopathological examination of the different four groups, one month $(1 \mathrm{M})$ postoperative. One Month

G-I (Control group): Grossly: Presence of mild congestion at the site of wound (black arrow).

Candle: Presence of very few congested blood vessels at the site of wound (black arrow).

Histopathologically: Photomicrograph of rectus abdominis showing connective tissue proliferation and leucocytic infiltrates by lymphocytes (H\&E; Bar= $100 \mu \mathrm{m}$ )

G-II (Group treated with Curcumin alone): Grossly: Presence of mild congestion at the site of injury with very small remnant of particles (black arrow).

Candle: (black arrow and head of arrow)

Histopathologically: Photomicrograph of rectus abdominis showing mild congested blood, fatty infiltrates (H\&E; Bar= $100 \mu \mathrm{m}$ ).

G-III (Group treated with Curcumin loaded on Nano-material of Zn Al -LDH): Grossly: Absence of congested blood vessels and complete dissolving of nanomaterial at the site of wound (black arrow).

Candle: Presence mild congested blood vessels and drug residue not present (white arrow).

Histopathologically: Photomicrograph of rectus abdominis showing minimal drug residue, connective tissue proliferate with no congestion (H\&E; Bar= $100 \mu \mathrm{m})$.

G-IV (Group treated with Zn/AI-LDH alone): Grossly: Presence of Nanopowder residue and absence of congestion at the site of wound (black arrow). Candle: presence of drug residue (black arrow).

Histopathologically: Photomicrograph of rectus abdominis showing wide gap distance with appearance of drug residue associated with minimal congestion (H\&E; Bar= $200 \mu \mathrm{m})$.

phase of wound healing with very small remnant of drug this coincide with [12] who reported that the curcumin has limited effect due to poor solubility and rapid metabolism. In G-III (Plate 3) Absence of congested blood vessels and complete dissolving of nanomaterial at the site of wound maximize the capability of Curcumin. In G-IV (Plate 3) Presence of Nano-powder residue and absence of congestion at the site of wound. While the microscopical examination of control group G-I (Plate 3) showed connective tissue proliferation and leucocytic infiltrates by lymphocytes considered the end of the proliferative phase disappearance and this coincide with who stated that there is an increase in fibroblasts during the proliferative phase in normal wound healing. In G-II (Plate 3 ) showed mild congested blood capillaries, In G-III (Plate 3) the microscopical examination of the wound site revealed minimal drug residue, connective tissue proliferation. In G-IV (Plate 3) showed drug residue associated with minimal congestion.

Some tissue components can emit autofluorescence when examined under fluorescent microscope including health smooth muscle fibers (normal muscle bundles ) and collagen [13].

Our results prove that when occur examination of healthy area of smooth muscle bundles under fluorescent microscope, emit the intrinsic autofluorescence but loose this ability when become degenerated and suffer from hyalinosis as Plate (4) in all groups G-I, G-II, G-III, while when the degenerative change reversed the autofluorescence ability of the smooth muscle fiber can be restored like in G-IV.

As employing the autofluorescence ability of collagen bundles present between two edges of the induced wound in muscle displaying a distant clear gap could be determined by using image $j$ software Plate (4), our results showed that the shortest length was in G-IV $($ Nanomaterial $)=451.100$, after that G-II (Curcumin only) $=$ 514.674, G-I (Control) $=753.335$, then G-III (Curcumin associated with nanomaterial $)=862.503$ respectively, that is to say the lowest scar tissue formation and less collagen production was in group G-IV. While in G-III the largest scar tissue formation and collagen production.

Collagen production and release begin on the $3^{\text {rd }}$ day and continue for 3 weeks. Collagens released from fibroblasts and their cross-linkage enhances wound tension strength. The amount and quality of collagen synthesis determine the wound tension strength, which is the mechanical integrity of the wound. The final phase of wound healing is the remodeling phase, which is characterized by the reorganization of collagen fibrils and gradually increasing wound tension strength [27-29]. An increase in wound tension strength positively affects wound healing in primary wounds $[27,29]$.

An increase fibrosis and collagen amount at the wound site do not always result in improved healing because an irregular sequence of collagen fibers can have a negative effect on wound healing [30,31].

In case of collagen deposition in G.I (Plate 4), the amount was large but it was irregular where the tensile strength of the muscle fibers very low, as well as presence of high number of blood capillaries confirm that this the end of proliferative phase with characteristic granulation tissue with high vasculature and early collagen deposition and this result coincide with [27] who explained the reduced wound strength was due to the irregular collagen fibers that arranged during the early period of wound healing even it was in high amount. While in G-II (Plate 4), the tensile strength of the muscle fibers is more as minimal vasculature considered the end of proliferative phase of wound healing, but collagen deposition was less regular than G-III and G-IV (Plate 4).

In case of G.III and G-IV (Plate 4), the regularity of collagen deposition proved, but the amount of this collagen differ where the 


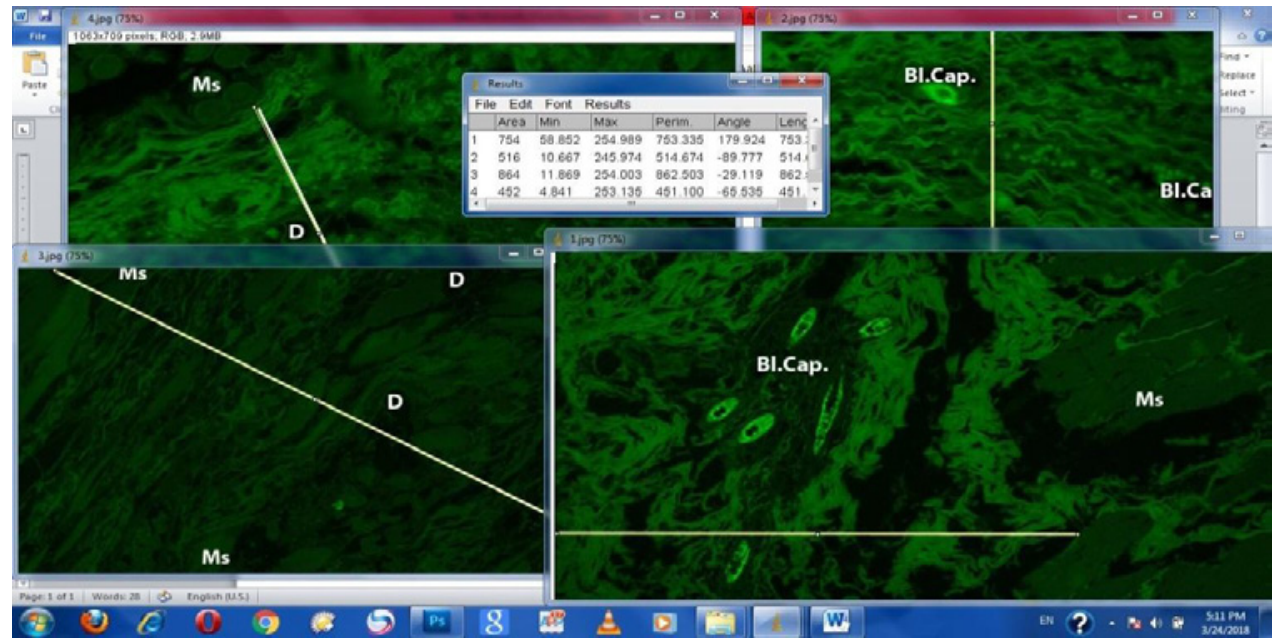

Plate 4: Showing auto fluorescence results under fluorescent microscope of the different four groups, one month postoperative. Data analysis of microphotographs of the four groups using image $\mathrm{j}$ software.

fact of the largest regular collagen fibers the more increased tensile strength of the wound equal the more improved wound healing that displayed in G-III (Plate 4) (Curcumin associated with nanomaterial) where the length of regular collagen fibers was $=862.503$ after that G-IV (Plate 4) (Nanomaterial) $=451.100$ the length of regular collagen fibers. So from all these data observed that the best wound healing was in G-III, G-IV, G-II, and then G-I respectively.

According to the histopathological investigation intramuscular implantation of $\mathrm{Zn} / \mathrm{Al}-\mathrm{LDH}$ cause no cytotoxicity for the local tissues around the inserted drugs or materials with no presences any signs of inflammatory response related to the materials antigenicity and confirmed by candling which confirmed the tissue integration with functional neovessels and without local microcirculatory dysfunction these results come in accordance with [32]. To the best of our knowledge, this is only one paper reports about the usage of imaging to access indirectly the biocompatibility \& wound healing of materials implanted in living tissues.

The rate of wound healing ability, biocompatibility, Antiinflammatory, No Antigenicity and excellent contraction rate of wound gab edges observed in Zinc Aluminum nanomaterial which confirmed by measuring their emitting to florescence and tensile muscles strength. The cause of theses good characters due to nature of zinc ion as considered as Kosmotrope ions which established stronger charge-dipole interactions with local water than chaotropes ions, form this point zinc ion modify the protein present in the wound area and promoting different function help healing and anti-inflammatory effects [33]. Besides the protein structure can be influenced by the nature on both anions and cations incorporated in the LDH structure [34].

On the same ground Zinc Aluminum nanomaterial help rapid wound healing through the formation of type-III fibers or reticular fibers around the implanted drugs. In addition to this fibers $\mathrm{Zn} /$ $\mathrm{Al}$ help in protein formation in the extracellular matrix, such as fibronectin. Fibronectin has a zinc-dependence binding domain called Gelatin-Binding Domain (GBD) in its structure, that interact

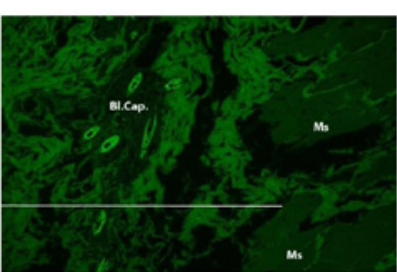

G.I

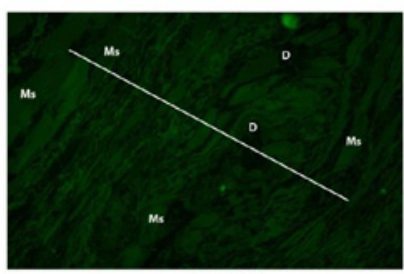

G.III

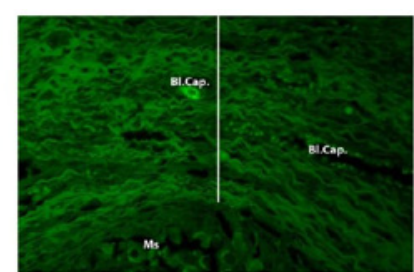

G.II

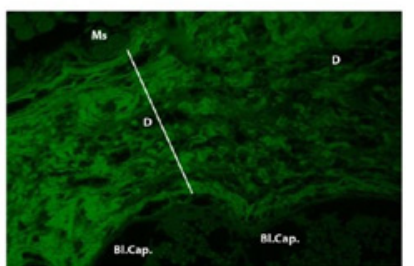

G.IV
Plate 5: Figure (G-I): Control group showing collagen autoflourescence between healing edges of rectus abdominis muscle, which measured by image $\mathrm{J}$ software $=753.335$, high number of blood capillaries BI. Cap., associated with edema, and hyalinosed muscle fibers Ms (x200).

Figure (G-II): Curcumin group showing collagen autoflourescent between healing edges of rectus abdominis muscle, which measured by image $\mathrm{J}$ software $=514.674$, blood capillaries BI. Cap. and more or less normal muscle fibers Ms (x200).

Figure (G-III): Crucium + Zn Al- LDH group showing collagen autoflourescent between healing edges of rectus abdominis muscle, which measured by image $\mathrm{J}$ software $=862.503$, large sized debris of the reminant powder in the tissue $D$, and hyalinosed muscle fibers Ms (x200).

Figure (G-IV): Zn Al LDH group showing collagen autoflourescent between healing edges of rectus abdominis muscle, which measured by image $\mathrm{J}$ software $=451.100$, large blood capillary BI. Cap., small sized debris of reminant powder in tissue $\mathbf{D}$, and restored muscle fibers to health state $\mathbf{M s}$ (x200).

with and help the Collagen formation [35]. The interaction of $\mathrm{Zn}^{2+}$ with collagen is reported in the literature [36].

The positive Charge present on the surface of $\mathrm{Zn} / \mathrm{Al} \mathrm{LDH}$ has an important role in the interaction between the inorganic materials and biomolecules or proteins which help tissue repair [37]. These proteins 
also of negative charge and help more electrostatic interactions with the $\mathrm{Zn} / \mathrm{Al} \mathrm{LDH}$ [32]. Besides the good healing activity and biocompatibility observed through the candling, histopathologically in $\mathrm{m}$ 4ouscles strength and in florescence emission might also attributed to the alkaline $\mathrm{pH}$ of the synthesized $\mathrm{LDH}$ as the acidic environment impair, prevent and restrict the cellular activity responsible for wound healing and tissue repair [32]. So maintenance of the alkaline media through the slowly dissociated LDH decreases the local tissue acidosis and helps the normal cell response [32].

In the Curcumin pure materials alone also the healing process were very good with good biocompatibility and no antigenicity, these might be attributed to the ability of Curcumin in increasing the cellular Proliferation and collagen synthesis at the wound site [38] confirmed by the candling and histopathological investigation besides their muscles strength and florescence emission. In addition Curcumin possesses significant antioxidant activity; the prevention of oxidation in tissues helps rapid and good healing process [39]. This antioxidant ability in Curcumin could be attributed to the phenolic and the methoxy groups in conjunction with the 1,3-diketone conjugated diene system, for scavenging of the oxygen radicals [40].

On the other hand when Curcumin loaded on $\mathrm{Zn} / \mathrm{Al} \mathrm{LDH}$ nanomaterial; the healing activity takes more time as prolonged their duration of action with delayed activity so this Nano composite very good in chronic wound treatment not acute one as Curcumin alone. This prolongation to the duration of action might be attributed to the role of the LDH which demonstrated a slow and a sustained release of the Curcumin in an acidic medium (wound site) leading to prolongation to the duration of action and decrease the absorption rate [41]. The divalent metals as zinc responsible for the positive charge on the LDH surface, thus making the intercalation with negatively charged drugs [42]. So due to the LDH structure casing a controllable sustained anion exchange which is $\mathrm{pH}$ dependent and mandatory for the controlled-release properties of this system leading to decreasing the absorption rate and prolongation to the duration of action [43]. Also previous literature studies demonstrated the successful intercalation of chemically isolated Curcumin into LDH and showed its slow release behavior [41]. On the same way presence of a large amount of $\mathrm{Zn}^{2+}$, the GBD domain captures a greater quantity of zinc ions slowing down the formation of fibronectin protein. This process lead to the delay formation of mature collagen fibers which cause the fibers to clump linger [32].

Drug release of the nanomaterials usually delayed for prolongation to the duration of action; from this point of view the release of the pure Curcumin and Curcumin/LDH nanoparticles had been measured. Nanoparticles improve bioavailability, sustained delivery and targeting of Curcumin to the particular site by delaying its release to the circulation and limiting effects to target cell. In our results and as shown in $[44,45]$, The in-vitro Release of free Curcumin was rapid within 24 hour ( $>87 \%$ ), incorporation of free Curcumin into Nano layers of $\mathrm{LDH}$ retarded this release up to $56 \%$ which indicates the controlled release of Curcumin from the LDH layers which lead to prolongation to the duration of action; that's is the main reason for presence of drug or nanomaterials remnants in the wound sites in both nanomaterial and Curcumin loaded on the nanomaterial.

\section{Conclusion}

$\mathrm{Zn} / \mathrm{Al} \mathrm{LDH}$, Curcumin and Curcumin nanohybrid revealed good tissue repair in acute and chronic wounds with good biocompatibility and healing activity with collagen formation, in addition to prolongation to the duration of action of the loaded materials or drugs with LDH nanomaterial in a controlled release manner.

\section{Supplementary Data}

Present Supplementary data for the preparation method.

\section{The Consent to Publish Section}

- Animal handling methods, including weighting and gavage procedures were carried out in accordance with and were approved by the Institutional Animal Care and Use Committee, Faculty of veterinary medicine, Beni- Suef University (Protocol of Animal Rights for Laboratory Experiments).

- $\quad$ No case studies were reported in this article

\section{Availability of Data and Material}

The authors emphasize the availability of data and materials

\section{Author Contribution}

This study was designed, directed and coordinated by A Farghali and M Fathy., as the principle investigators, provided conceptual and technical guidance. R Mahmoud and N Mohamed planned and performed the preparation and characterization of the used materials; the data analysed with S El-Dek. F Abo El-Ela2 and N Safwat planned and performed the application experiments and the data analyzed with H. A. El-Banna.

\section{References}

1. $\mathrm{Li} \mathrm{Y}, \mathrm{Bi} \mathrm{H}-\mathrm{Y}$, Shi $\mathrm{X}-\mathrm{Q}$. "Simultaneous adsorption of heavy metal and organic pollutant onto citrate-modified layered double hydroxides with dodecylbenzenesulfonate." Environmental Engineering Science. 2015; 32: 666-675.

2. Goh KH, Lim TT, Dong ZL. "Application of layered double hydroxides for removal of oxyanions: A review." Water Research journal. 2008; 42: 13431368.

3. Chimene D, Alge DL, Gaharwar AK. "Two-Dimensional nanomaterials for biomedical applications: emerging trends and future prospects." Adv Mater journal. 2015; 27: 7261-7284

4. Chatterjee A, Bharadiya P, Hansora D. "Layered double hydroxide based bionanocomposites." Applied Clay Science. 2019; 177: 19-36.

5. El-Shahawya AAG, Abo El-Elab FI, Mohameda NA, Eldinea ZE, El Rouby WMA. "Synthesis and evaluation of layered double hydroxide/doxycycline and cobalt ferrite/chitosan nanohybrid efficacy on gram positive and gram negative bacteria." Materials Science \& Engineering C. 2018; 91: 361-371.

6. Abdel Moaty SA, Farghali AA, Khaled R. "Preparation, characterization and antimicrobial applications of Zn-Fe LDH against MRSA." Materials Science and Engineering C. 2016; 68: 184-193.

7. Abo El-Ela FI, Mahmoud RK, Mohamed NA, Abdel Moaty SA. "New Approach in Ulcer Prevention and Wound Healing Treatment using Doxycycline and Amoxicillin/LDH Nanocomposites." Scientific Reports. 2019; 9: 6418.

8. Yasaei M, Khakbiz M, Ghasemi E, Zamanian A. "Synthesis and

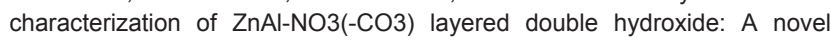
structure for intercalation and release of simvastatin." Applied Surface Science. 2019; 467-468: 782-791. 
9. A Bhattacharjee, SkH. Rahaman, S Saha, M Chakraborty, S Chakraborty. "Determination of half maximal inhibitory concentration of CaAl layered double hydroxide on cancer cells and its role in the apoptotic pathway." J Applied Clay Science. 2019; 168: 31-35

10. Munireddy, S., Kavalukas SL, Barbul A. "Intra-abdominal healing: gastrointestinal tract and adhesions. ." Surg Clin North Am. Journal. 2010; 90: 1227-1236.

11. Bhowmik D, Gopinath $H$, Pragati Kumar B, Duraive S. Sampath Kumar KP. "Controlled Release Drug Delivery Systems" "THE PHARMA INNOVATION" JOURNAL. 2012; 1.

12. D Akbik, G Maliheh, C Wojciech, R Ramin. "Review article: Curcumin as a wound healing agent." Life Sciences. 2014; 116: 1-7.

13. S Deeb, KH Nesr, E Mahdy, M Badawey, M Badei. "Autofluorescence of routinely hematoxylin and eosin-stained sections without exogenousmarkers." African Journal of Biotechnology. 2008; 7: 504-507.

14. Kumar S, Mahesh A, Mahadevan S, Mandal AB. "Synthesis and characterization of curcumin loaded polymer/lipid based nanoparticles and evaluation of their antitumor effects on MCF-7 cells." Biochimica et Biophysica Acta. 2014; 1840: 1913-1922.

15. Mohanty C, Sahoo SK. "The in vitro stability and in vivo pharmacokinetics of curcumin prepared as an aqueous nanoparticulate formulation." Biomaterials. 2010; 31: 6597-6611.

16. Yallapu M, Gupta BK, Jaggi M, Chauhan SC. "Fabrication of curcumin encapsulated PLGA nanoparticles for improved therapeutic effects in metastatic cancer cells." Journal of Colloid and Interface Science. 2010; 351 19-29.

17. Anitha A, Deepagan VG, Rani VV, Menon D, Nair SV, Jayakumar R. "Preparation, characterization, in vitro drug release and biological studies of curcumin loaded dextran sulphate-chitosan nanoparticles." Carbohydrate Polymers. 2011; 84: 1158-1164.

18. Kamkanam M, Samindra S, Kottegoda N. "Encapsulation of curcumin into layered double hydroxides." Nanotechnol Rev. 2014; 3: 579-589.

19. Moaty SA, Farghali AA, Moussa M, Khaled R. "Remediation of waste wate by Co-Fe layered double hydroxide and its catalytic activity." Journal of the Taiwan Institute of Chemical Engineers. 2017; 71: 441-453.

20. Bryant BEM. Scanning tunnelling microscopy of bilayer manganites. Doctoral thesis. 2010.

21. Oryan A, Tabatabaei NA, Moshiri A, Mohammadalipour A, Tabandeh MR. "Modulation of cutaneous wound healing by silymarin in rats." J Wound Care. 2012; 21: 457-464

22. Kim SS, Layton C, Bancroft JD. Bancroft's Theory and Practice of Histological Techniques. Imprint of Elsevier Limited. China. 2013.

23. Thevenot F, Szymanski R, Chaumette P. "Preparation and characterization of Al-rich Zn-Al hydrotalcite-like compounds." Clays and Clay Minerals. 1989; 37: 396-402.

24. Samindra SKM, Kottegoda N. "Encapsulation of curcumin into layered double hydroxides." Nanotechnol Rev. 2014; 3: 579-589.

25. Parida KM, Sahoo M, Singha S. "Synthesis and characterization of a Fe (III)Schiff base complex in a Zn-AI LDH host for cyclohexane oxidation." Journa of Molecular Catalysis A: Chemical. 2010; 329: 7-12.

26. M Thommes, AV Neimark, JP Olivier, F Rodriguez-Reinoso, J Rouquerol. "Physisorption of gases, with special reference to the evaluation of surface area and pore size distribution (IUPAC Technical Report)." Pure Appl. Chem. 2015; 87: 1051-1069.
27. Zeren S, S Kesici, U Kesici. "Effects of Levobupivacaine on Wound Healing." Anesth Analg. 2013; 116: 495-499.

28. Leverson SM, Heever EF, Crowley LV, Oates JF, Berard CW, Rosen H. "The healing of rat skin wounds." Ann Surg. 1965; 161: 293-308.

29. Mackay D, Miller A. Nutritional Support for Wound Healing. 2003.

30. Soo C, Shaw WW, Zhang X. "Differential expression of matrix metalloproteinases and their tissue-derived inhibitors in cutaneous wound repair." Plast Reconstr Surg. 2000; 105: 638-647.

31. Nagler A, M Ohana, M Leiba, L Levdansky, R Gorodetsky. "Effect of halofuginone, a collagen alpha1(I) inhibitor, on wound healing in normal and irradiated skin: implication for hematopoietic stem cell transplantation." Acta Haematol. 2007; 118: 77-83.

32. Cunha VR. Souza RB, Martins AC, Koh IHJ, Constantino VRL. "Accessing the biocompatibility of layered double hydroxide by intramuscular implantation: histological and microcirculation evaluation." Scientific Reports. 2016; 6: 30547

33. Wang L, Y Guo, P Li, Y Song. "Specific Effects on the Assembly of Collagen Layers Mediated by Magnesium Ion on Mica Surface." J Phys Chem B. 2014; 118: $511-518$

34. Nostro PL, Ninham BW. "Hofmeister Phenomena: An Update on Ion Specificity in Biology." Chem Rev. 2012; 112: 2286-2322.

35. Graille M, Pagano M, Rose T, Ravaux MR, Tilbeurgh H. "Zinc induces structural reorganization of gelatin binding domain from human fibronectin and affects collagen binding." Structure. 2010; 18: 710-718.

36. Yu Y, D Fan. "Coordination study of recombinant human-like collagen and zinc (II). Spectrochim." Acta A Mol Biomol.Spectrosc. 2011; 81: 412-416.

37. Gu Z, Atherton JJ, Xu ZP. "Hierarchical layered double hydroxide nanocomposites: structure, synthesis and applications." Chem. Commun. 2015; 51: 3024-3036.

38. Panchatcharam M, Miriyala S, Gayathri VS, Suguna SL. "Curcumin improves wound healing by modulating collagen and decreasing reactive oxygen species." Molecular and Cellular Biochemistry. 2006; 290: 87-96.

39. Phan TT, P See, ST Lee, SY Chan. "Protective effects of curcumin against oxidative damage on skin cells in vitro: Its implications for wound healing." J Trauma. 2001; 51: 927-931.

40. Wright JS. "Predicting the antioxidant activity of curcumin and curcuminoids." J Mol Struc. 2002; 591: 207-217.

41. Megalathan A, S Kumarage, A Dilhari, MM Weerasekera, S Samarasinghe, $\mathrm{N}$ Kottegoda. "Natural curcuminoids encapsulated in layered double hydroxides: a novel antimicrobial nanohybrid Megalathan et al." Chemistry Central Journal. 2016; 10: 35

42. Wei PR, SH Cheng, Liaom WN, Kao Cl, Weng CF, Lee CH. "Synthesis of chitosan-coated near-infrared layered double hydroxide nanoparticles for in vivo optical imaging." J Mater Chem. 2012; 22: 5503-5513.

43. Yang JH, Han YS, Park M, Park T, Hwang SJ, Choy JH. "New inorganicbased drug delivery system of indole-3-acetic acid-layered metal hydroxide nanohybrids with controlled release rate." Chem Mater. 2007; 19: 2679-2685.

44. Kuehn T, Poellmann H. "Synthesis and characterization of Zn-Al layered double hydroxides intercalated with 1- to 19-carbon carboxylic acid anions." Clays and Clay Minerals. 2010; 58: 596-605

45. Zhu C. "A novel thiolated human-like collage zinc complex as a promising zinc supplement: Physicochemical characteristics and biocompatibility." Mater Sci Eng C Mater Biol Appl. 2014; 44: 411-416. 